\title{
Human Resources Management using Interval Valued Intuitionistic Fuzzy Analytic Hierarchy Process
}

\author{
Ali Fahmi \\ Department of Management \\ Engineering \\ Istanbul Technical University \\ Istanbul, Turkey \\ fahmi@itu.edu.tr
}

\author{
Azad Derakhshan \\ Department of Management \\ Engineering \\ Istanbul Technical University \\ Istanbul, Turkey \\ derakhshan@itu.edu.tr
}

\author{
Cengiz Kahraman \\ Department of Industrial \\ Engineering \\ Istanbul Technical University \\ Istanbul, Turkey \\ kahramanc@itu.edu.tr
}

\begin{abstract}
Human resource management (HRM) is a function in organizations designed to maximize employee performance in service of their employer's strategic objectives. Linguistic evaluations rather than numerical evaluations are preferred when making comparative assessments. These assessments can be expressed by interval-valued intuitionistic fuzzy sets easier than ordinary fuzzy sets. In this paper, we used a fuzzy analytic hierarchy process (AHP) method based on interval-valued intuitionistic fuzzy sets for the selection among the people applying for a position at a university.
\end{abstract}

Keywords- human resource management (HRM), interval-valued intuitionistic fuzzy set, analytic hierarchy process (AHP)

\section{INTRODUCTION}

Human resource management (HDM) refers to finding, developing, and maintaining an effective and efficient workforce [1]. First step is to find the right people for right positions. Similar to other decision problems, personnel selection is a complicated and multi-criteria decision making process [2, 3, 4]. So that, it includes qualitative and quantitative attributes such as cooperation spirit, organizing ability, scientific background and leadership for qualitative attributes; age, foreign language score, and written examination score for quantitative attributes. Evaluation of most of these attributes contains uncertainty and imprecision. Decision makers mostly deal with these evaluations by linguistic scores. For these reasons, we need fuzzy logic and fuzzy linguistic terms to model the problem and select the best alternative.

Recently, extensions of fuzzy sets such as type-II fuzzy sets, hesitant fuzzy sets and intuitionistic fuzzy sets (IFS) are being applied in many studies. Atanassov [5] developed IFS to deal with hesitancy concept in fuzzy sets. He defined the nonmembership function together with the membership function of fuzzy sets. These functions imply the hesitancy degree of an interval valued intuitionistic fuzzy set. Later, Atanassov [6] combined the concept of interval valued membership degree and IFS to develop interval valued intuitionistic fuzzy sets (IVIFS).

In this study, we use an analytic hierarchy process (AHP) model, based on interval valued intuitionistic fuzzy sets. This model is used to select the most appropriate person by the human resource department. The rest of the paper is organized as follows: Section 2 provides a literature review on HRM activities. In Section 3 is about interval valued intuitionistic fuzzy sets. Then, interval valued intuitionistic fuzzy AHP is presented in Section 4. A real application is given in Section 5. Finally, conclusion and future works are presented in Section 6.

\section{HUMAN RESOURCE MANAGEMENT}

As mentioned before, HRM encompasses the selection of the right people for right positions. In 
other words, managers consider the process of selecting right people to become more competitive on a global basis, to improve quality, innovation, and customer service, and to retain during mergers and acquisitions [1].

Any improper personnel selection would lead to undesirable waste of resources. It would increase organizational costs of engaging, training, and firing of poor and ill-suited employees in the long run [7]. Also, the personnel evaluation and selection is a process that can extremely influence the future position and the performance of an organization [8]. Thus, the more systematic and structured personnel selection, the better organizational performance.

Gungor [2] applied fuzzy AHP model for personnel selection problem. They converted all pairwise comparisons into triangular fuzzy numbers and considered criteria as follows: general factors such as work experience, level of foreign language, education, analytical thinking of integrated systems, as basic computer skills, complementary factors such as decision making, team work, and individual factors as age, culture, and appearance. Daneshvar and Erkan [9] used fuzzy AHP to select academic staff. They used triangular fuzzy numbers as well. Shahhoseini and Sebt [10] developed fuzzy AHP and adaptive neuro-fuzzy inference system (ANFIS) to assign workforce in construction projects. Technical, behavioral, and contextual competencies are considered to be the main criteria. Kelemenis and Askounis [11] developed a TOPSIS-based multicriteria approach to select the best personnel. Dursun and Karsak [12] developed a fuzzy TOPSIS model for personnel selection. They applied a basic linguistic term set (BLTS) and transformed into 2tuple linguistic representations. Chang et al. [13] developed the fuzzy Delphi method by triangular fuzzy numbers for human resource management.

Karatop et al. [4] determined the criteria as emotional quotient (EQ), performance, loyalty, experience, communication ability, foreign language, IT ability in their talent management study in a manufacturing system to determine competency and job importance levels. Creativity, problem solving, negotiation, strategic planning, communication skill, experience, and education are among the managerial skills as criteria and fuzzy TOPSIS is implemented to rank alternatives [14]. Aksakal et al. [15] applied TOPSIS method for personnel selection process by considering following criteria: communication, decision making, teamwork, leadership, interpersonal skills, and technical and functional qualifications.

According to the above-mentioned literature review, we considered language skills (LS), team work ability (TWA), research experience (RE), grade point average (GPA), teaching ability (TA), and behavior and appearance (BA) as criteria for research assistant selection.

\section{INTERVAL VALUED INTUITIONISTIC FUZZY SETS}

Atanassov's intuitionistic fuzzy sets [5] take into account the membership value as well as the nonmembership value for describing any $x$ in $X$ such that the sum of membership and non-membership is less than or equal to 1 . In the following we define the basic definitions of intuitionistic fuzzy sets

Definition 1. Let $X \neq \varnothing$ be a given set. An intuitionistic fuzzy set in $X$ is an object $\widetilde{\mathrm{A}}$ given by

$$
\widetilde{\mathrm{A}}=\left\{\left\langle\mathrm{x}, \mu_{\widetilde{\mathrm{A}}}(\mathrm{x}), \mathrm{v}_{\widetilde{\mathrm{A}}}(\mathrm{x})\right\rangle ; \mathrm{x} \in \mathrm{X}\right\}
$$

where $\mu_{\widetilde{\mathrm{A}}}: \mathrm{X} \rightarrow[0,1]$ and $\mathrm{v}_{\widetilde{\mathrm{A}}}: \mathrm{X} \rightarrow[0,1]$ satisfy the condition

$$
0 \leq \mu_{\widetilde{\mathrm{A}}}(\mathrm{x})+\mathrm{v}_{\widetilde{\mathrm{A}}}(\mathrm{x}) \leq 1
$$

for every $x \in X$.

Definition 2. $\alpha$-cut of an intuitionistic fuzzy set is given by the following equations:

For an intuitionistic fuzzy set the $\alpha$-cut is defined in [2] as the set

$$
\widetilde{\mathrm{A}}_{\alpha}=\left\{\mathrm{x} \in \mathrm{X} \mid \mu_{\widetilde{\mathrm{A}}}(\mathrm{x}) \geq \alpha, \mathrm{v}_{\widetilde{\mathrm{A}}}(\mathrm{x}) \leq 1-\alpha\right\}
$$

Definition 3. Let $\mathrm{D} \subseteq[0,1]$ be the set of all closed subintervals of the interval and $X$ be a universe of discourse. An interval-valued intuitionistic fuzzy set $\widetilde{\mathrm{A}}$ over $X$ is an object having the form

$$
\widetilde{\mathrm{A}}=\left\{<\mathrm{x}, \mu_{\widetilde{\mathrm{A}}}(\mathrm{x}), \mathrm{v}_{\widetilde{\mathrm{A}}}(\mathrm{x})>\mid \mathrm{x} \in \mathrm{X}\right\}
$$

where

$$
\mu_{\widetilde{\mathrm{A}}} \rightarrow \mathrm{D} \subseteq[0,1], \mathrm{v}_{\widetilde{\mathrm{A}}}(\mathrm{x}) \rightarrow \mathrm{D} \subseteq[0,1]
$$

with the condition $0 \leq \sup _{\widetilde{\mathrm{A}}}(\mathrm{x})+\operatorname{supv}_{\widetilde{\mathrm{A}}}(\mathrm{x}) \leq 1$, $\forall \mathrm{x} \in \mathrm{X}$ 
The intervals $\mu_{\widetilde{\mathrm{A}}}(\mathrm{x})$ and $\mathrm{v}_{\widetilde{\mathrm{A}}}(\mathrm{x})$ denote the membership function and the non-membership function of the element $x$ to the set $\widetilde{A}$, respectively. Thus for each $\mathrm{x} \in \mathrm{X}, \mu_{\widetilde{\mathrm{A}}}(\mathrm{x})$ and $v_{\widetilde{\mathrm{A}}}(\mathrm{x})$ are closed intervals and their starting and ending points are denoted by $\mu_{\widetilde{\mathrm{A}}}^{-}(\mathrm{x}), \mu_{\widetilde{\mathrm{A}}}^{+}(\mathrm{x}), \quad v_{\widetilde{\mathrm{A}}}^{-}(\mathrm{x})$ and $v_{\widetilde{\mathrm{A}}}^{+}(\mathrm{x})$, respectively. Interval-valeud intuitionistic fuzzy set $\widetilde{A}$ is then denoted by

$$
\widetilde{\mathrm{A}}=\left\{<\mathrm{x},\left[\mu_{\tilde{\mathrm{A}}}^{-}(\mathrm{x}), \mu_{\tilde{\mathrm{A}}}^{ \pm}(\mathrm{x})\right],\left[v_{\widetilde{\mathrm{A}}}^{-}(\mathrm{x}), v_{\widetilde{\mathrm{A}}}^{+}(\mathrm{x})\right]>\mid \mathrm{x} \in \mathrm{X}\right\}
$$

where

$$
0 \leq \mu_{\widetilde{\mathrm{A}}}^{+}(\mathrm{x})+v_{\widetilde{\mathrm{A}}}^{+}(\mathrm{x}) \leq 1, \mu_{\widetilde{\mathrm{A}}}^{-}(\mathrm{x}) \geq 0, v_{\widetilde{\mathrm{A}}}^{\bar{\tau}}(\mathrm{x}) \geq 0 .
$$

For each element $x$, we can compute the unknown degree (hesitancy degree) of an interval-valued intuitionistic fuzzy set of $\mathrm{x} \in \mathrm{X}$ in $\widetilde{\mathrm{A}}$ defined as follows:

$\pi_{\widetilde{A}}(x)=1-\mu_{\widetilde{\AA}}(x)-v_{\widetilde{A}}(x)=\left[1-\mu_{\tilde{A}}^{+}(x)-v_{\tilde{A}}^{+}(x), 1-\mu_{\tilde{A}}^{\sim}(x)-v_{\widetilde{A}}^{-}(x)\right]$

For convenience, let $\mu_{\widetilde{\mathrm{A}}}(\mathrm{x})=\left[\mu_{\tilde{\mathrm{A}}}^{-}(\mathrm{x}), \mu_{\tilde{\mathrm{A}}}^{+}(\mathrm{x})\right]$

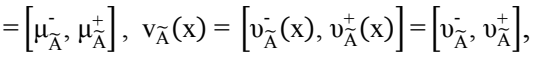

$$
\begin{aligned}
& \text { so } \widetilde{\mathrm{A}}=\left(\left[\mu_{\widetilde{\mathrm{A}}}^{-}, \mu_{\widetilde{\mathrm{A}}}^{+}\right],\left[v_{\widetilde{\mathrm{A}}}^{-}, v_{\widetilde{\mathrm{A}}}^{+}\right]\right) \text {. }
\end{aligned}
$$

\section{INTERVAL VALUED INTUITIONISTIC FUZZY AHP}

The multi-criteria decision making methodology used in this paper is based on the Wu et al.'s [16] work. They propose an approach for multi-criteria decision making (MCDM) problems with intervalvalued intuitionistic fuzzy preference relations (IVIFPRs). Let $\widetilde{R}=\left(\tilde{r}_{i j}\right)_{n \times n}=\left(\left[\mu_{i j}^{-}, \mu_{i j}^{+}\right],\left[v_{i j}^{-}, v_{i j}^{+}\right]\right)_{n \times n}$ be an interval-valued intuitionistic judgment matrix as follows:

$\widetilde{\mathrm{R}}=\left[\begin{array}{ccc}\left(\left[\mu_{11}^{-}, \mu_{11}^{+}\right],\left[\mathrm{v}_{11}^{-}, \mathrm{v}_{11}^{+}\right]\right) & \cdots & \left(\left[\mu_{\mathrm{ln}}^{-}, \mu_{1 \mathrm{n}}^{+}\right],\left[\mathrm{v}_{\mathrm{in}}^{-}, \mathrm{v}_{1 \mathrm{n}}^{+}\right]\right) \\ \vdots & \ddots & \vdots \\ \left(\left[\mu_{\mathrm{n} 1}^{-}, \mu_{\mathrm{n} 1}^{+}\right],\left[\mathrm{v}_{\mathrm{n} 1}^{-}, \mathrm{v}_{\mathrm{n} 1}^{+}\right]\right) & \cdots & \left(\left[\mu_{\mathrm{nn}}^{-}, \mu_{\mathrm{nn}}^{+}\right],\left[\mathrm{v}_{\mathrm{nn}}^{-}, \mathrm{v}_{\mathrm{nn}}^{+}\right]\right)\end{array}\right]$

The reciprocal value of $\left(\left[\mu_{\mathrm{ij}}^{-}, \mu_{\mathrm{ij}}^{+}\right],\left[\mathrm{v}_{\mathrm{ij}}^{-}, \mathrm{v}_{\mathrm{ij}}^{+}\right]\right)$in $\widetilde{\mathrm{R}}$ is $\left(\left[\mathrm{v}_{\mathrm{ji}}^{-}, \mathrm{v}_{\mathrm{ji}}^{+}\right],\left[\mu_{\mathrm{ji}}^{-}, \mu_{\mathrm{ji}}^{+}\right]\right)$. For instance, the reciprocal value of $\left(\left[\mu_{\mathrm{n} 1}^{-}, \mu_{\mathrm{n} 1}^{+}\right],\left[\mathrm{v}_{\mathrm{n} 1}^{-}, \mathrm{v}_{\mathrm{n} 1}^{+}\right]\right)$is $\left(\left[\mathrm{v}_{1 \mathrm{n}}^{-}, \mathrm{v}_{1 \mathrm{n}}^{+}\right],\left[\mu_{1 \mathrm{n}}^{-}, \mu_{1 \mathrm{n}}^{+}\right]\right)$.
The score judgment matrix of $\widetilde{R}$ is represented by the matrix $\widetilde{\mathrm{S}}=\left(\tilde{\mathrm{s}}_{\mathrm{ij}}\right)_{\mathrm{n} \times \mathrm{n}}=\left[\mu_{\mathrm{ij}}^{-}-\mathrm{v}_{\mathrm{ij}}^{+}, \mu_{\mathrm{ij}}^{+}-\mathrm{v}_{\mathrm{ij}}^{-}\right]$as follows:

$$
\tilde{\mathrm{S}}=\left[\begin{array}{ccc}
{\left[\mu_{11}^{-}-\mathrm{v}_{11}^{+}, \mu_{11}^{+}-\mathrm{v}_{11}^{-}\right]} & \cdots & {\left[\mu_{1 \mathrm{n}}^{-}-\mathrm{v}_{11}^{+}, \mu_{1 \mathrm{n}}^{+}-\mathrm{v}_{\mathrm{ln}}^{-}\right]} \\
\vdots & \ddots & \vdots \\
{\left[\mu_{\mathrm{n} 1}^{-}-\mathrm{v}_{\mathrm{n} 1}^{+}, \mu_{\mathrm{n} 1}^{+}-\mathrm{v}_{\mathrm{n} 1}^{-}\right]} & \cdots & {\left[\mu_{\mathrm{nn}}^{-}-\mathrm{v}_{\mathrm{nn}}^{+}, \mu_{\mathrm{nn}}^{+}-\mathrm{v}_{\mathrm{nn}}^{-}\right.}
\end{array}\right]
$$

The interval multiplicative matrix

$$
\begin{aligned}
& \widetilde{\mathrm{A}}=\left(\tilde{\mathrm{a}}_{\mathrm{ij}}\right)_{\mathrm{n} \times \mathrm{n}}=\left[10^{\left(\mu_{\mathrm{ijj}}^{-}-\mathrm{v}_{\mathrm{ij}}^{+}\right)}, 10^{\left(\mu_{\mathrm{ij}}^{+}-\mathrm{v}_{\mathrm{ij}}^{-}\right)}\right] \text {is given as follows. }
\end{aligned}
$$

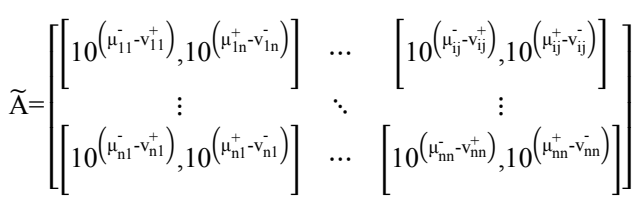

The steps of the fuzzy multicriteria decision making method are summarized in the following:

Step 1: Assign the interval-valued intuitionistic preferences for each pair of alternatives and obtain the interval-valued intuitionistic preference relation $\widetilde{R}=\left(\tilde{r}_{\mathrm{ij}}\right)_{\mathrm{n} \times \mathrm{n}}$.

Step 2: Calculate the score judgment matrix $\tilde{\mathrm{S}}=\left(\tilde{\mathrm{s}}_{\mathrm{ij}}\right)_{\mathrm{n} \times \mathrm{n}}$ and the interval multiplicative matrix $\widetilde{\mathrm{A}}=\left(\tilde{\mathrm{a}}_{\mathrm{ij}}\right)_{\mathrm{n} \times \mathrm{n}}$.

Step 3: Determine the priority vector of the interval multiplicative matrix $\widetilde{\mathrm{A}}=\left(\tilde{\mathrm{a}}_{\mathrm{ij}}\right)_{\mathrm{n} \times \mathrm{n}}$ by calculating the $\widetilde{\mathrm{w}}_{\mathrm{i}}$ interval for each criterion using Eq. (9)

$$
\widetilde{\mathrm{w}}_{\mathrm{i}}=\left[\frac{\sum_{\mathrm{j}=1}^{\mathrm{n}} \widetilde{\mathrm{a}}_{\mathrm{ij}}^{-}}{\sum_{\mathrm{i}=1}^{\mathrm{n}} \sum_{\mathrm{j}=1}^{\mathrm{n}} \tilde{\mathrm{a}}_{\mathrm{ij}}^{+}}, \frac{\sum_{\mathrm{j}=1}^{\mathrm{n}} \tilde{\mathrm{a}}_{\mathrm{ij}}^{+}}{\sum_{\mathrm{i}=1}^{\mathrm{n}} \sum_{\mathrm{j}=1}^{\mathrm{n}} \tilde{\mathrm{a}}_{\mathrm{ij}}^{-}}\right]
$$

Step 4: Construct the possibility degree matrix $\mathrm{P}=\left(\mathrm{p}_{\mathrm{ij}}\right)_{\mathrm{m} \times \mathrm{n}}$ by comparing the obtained weights in Step 3. To do this, use Eq. (10):

$$
\mathrm{P}\left(\mathrm{w}_{\mathrm{i}} \geq \mathrm{w}_{\mathrm{j}}\right)=\frac{\min \left\{\mathrm{L}_{\mathrm{w}_{\mathrm{i}}}+\mathrm{L}_{\mathrm{w}_{\mathrm{j}}} \max \left(\mathrm{w}_{\mathrm{i}}{ }^{+}-\mathrm{w}_{\mathrm{j}}, 0\right)\right\}}{\mathrm{L}_{\mathrm{w}_{\mathrm{i}}}+\mathrm{L}_{\mathrm{w}_{\mathrm{j}}}}
$$

Where $\quad \mathrm{L}_{\mathrm{w}_{\mathrm{i}}}=\mathrm{w}_{\mathrm{i}}^{+}-\mathrm{w}_{\mathrm{i}}^{-} \quad$ and $\quad \mathrm{L}_{\mathrm{w}_{\mathrm{j}}}=\mathrm{w}_{\mathrm{j}}^{+}-\mathrm{w}_{\mathrm{j}}^{-}$ and $\mathrm{p}_{\mathrm{ij}} \geq 0, \mathrm{p}_{\mathrm{ij}}+\mathrm{p}_{\mathrm{ji}}=1, \mathrm{p}_{\mathrm{ii}}=1 / 2$.

Step 5: Prioritize the $\mathrm{P}=\left(\mathrm{p}_{\mathrm{ij}}\right)_{\mathrm{m} \times \mathrm{n}}$ by Eq. (11):

$$
\mathrm{w}_{\mathrm{i}}=\frac{1}{\mathrm{n}}\left(\sum_{\mathrm{j}=1}^{\mathrm{n}} \mathrm{p}_{\mathrm{ij}}+\frac{\mathrm{n}}{2}-1\right)
$$


Step 6: Normalize the weights vector obtained in Step 5.

The scale given in Table 1 is used to assign the interval-valued intuitionistic preferences.

Table I. Linguistic scale and its corresponding IVIFS

\begin{tabular}{|c|c|}
\hline Linguistic Terms & $\begin{array}{c}\text { Membership \& Non-membership } \\
\text { values }\end{array}$ \\
\hline Absolutely Low (AL) & $([0,0.1],[0.8,0.9])$ \\
\hline Very Low (VL) & $([0.1,0.2],[0.7,0.8])$ \\
\hline Low (L) & $([0.2,0.3],[0.6,0.7])$ \\
\hline Medium Low (ML) & $([0.3,0.4],[0.5,0.6])$ \\
\hline Approximately Equal (AE) & $([0.4,0.5],[0.4,0.5])$ \\
\hline Medium High (MH) & $([0.5,0.6],[0.3,0.4])$ \\
\hline High (H) & $([0.6,0.7],[0.2,0.3])$ \\
\hline Very High (VH) & $([0.7,0.8],[0.1,0.2])$ \\
\hline Absolutely High (AH) & $([0.8,0.9],[0,0.1])$ \\
\hline
\end{tabular}
$0.5])$

For exactly equal, we assign $\mathrm{EE}=([0.5,0.5],[0.5$,

\section{APPLiCATION to Human Resources MANAGEMENT}

This section contains an application of interval valued intuitionistic fuzzy sets to make decision in human resource management. This problem represents an AHP model for assistant selection process in HRM department of a university. We used above-mentioned linguistic scales for pairwise comparisons. The steps of presented method are applied as following:

Step 1. This step includes comparison of each pair of criterion with respect to the goal and comparison of alternatives with respect to the criteria. Tables 2-3 present some example matrices reflecting preferences. Then, these linguistic preferences transform to IVIFS to obtain preference relation $\widetilde{R}$.

Step 2. We calculate judgment score matrices in this step using Eq. (7). Score judgment matrix of alternatives with respect to LS is as following:

$$
\tilde{S}=\left[\begin{array}{ccc}
{[0.0,0.0]} & {[-0.7,-0.5]} & {[-0.7,-0.5]} \\
{[0.5,0.7]} & {[0.0,0.0]} & {[-0.1,0.1]} \\
{[0.5,0.7]} & {[-0.1,0.1]} & {[0.0,0.0]}
\end{array}\right] .
$$

Next, we calculate interval multiplicative matrix $\widetilde{A}$ using Eq. (8) as following:

$$
\widetilde{A}=\left[\begin{array}{lll}
{[1.000,1.000]} & {[0.200,0.316]} & {[0.200,0.316]} \\
{[3.162,5.012]} & {[1.000,1.000]} & {[0.794,1.259]} \\
{[3.162,5.012]} & {[0.794,1.259]} & {[1.000,1.000]}
\end{array}\right]
$$

Step 3. In this step, we derermine the priority vector of the interval multiplicative matrices by Eq. (9). Priority vector of matrix $\widetilde{A}$ equals:

$$
\widetilde{\mathrm{w}}=\left[\begin{array}{l}
{[0.086,0.144]} \\
{[0.306,0.643]} \\
{[0.306,0.643]}
\end{array}\right] .
$$

Step 4. In this step, we construct the possibility degree matrix P using Eq. (10). Possibility degree matrix of alternative with respect to LS is as following:

$$
\mathrm{P}=\left[\begin{array}{lll}
0.500 & 0.000 & 0.000 \\
1.000 & 0.500 & 0.500 \\
1.000 & 0.500 & 0.500
\end{array}\right]
$$

Steps 5 and 6 . Then, we prioritize the possibility degree matrices and normalize the values. The below vectors show weights and normalized weights for each alternative with respect to LS.

$$
\mathrm{w}=\left[\begin{array}{l}
0.333 \\
0.833 \\
0.833
\end{array}\right], \quad \text { Normalized } \mathrm{w}=\left[\begin{array}{l}
0.167 \\
0.417 \\
0.417
\end{array}\right]
$$

Table 4 illustrates normalized weights of all criteria and alternatives. The priority of each alternative is also presented in Table 4.

Table II. Linguistic pairwise comparisons of criteria with respect to the goal

\begin{tabular}{|c|c|c|c|c|c|c|}
\hline & LS & TWA & RE & GPA & TA & BA \\
\hline LS & E & MH & AE & ML & L & H \\
\hline TWA & ML & E & ML & L & L & AE \\
\hline RE & AE & MH & E & ML & ML & H \\
\hline GPA & MH & H & MH & E & AE & H \\
\hline TA & H & H & MH & AE & E & VH \\
\hline BA & L & AE & L & L & VL & E \\
\hline
\end{tabular}

Table III. Linguistic pairwise comparisons of alternatives with respect to LS.

\begin{tabular}{|c|c|c|c|}
\hline & Alt. 1 & Alt. 2 & Alt. 3 \\
\hline Alt. 1 & E & VL & VL \\
\hline Alt. 2 & VH & E & AE \\
\hline Alt. 3 & VH & AE & E \\
\hline
\end{tabular}


Table IV. Weighted decision matrix and priorities.

\begin{tabular}{|c|c|c|c|c|c|c|c|}
\hline \multicolumn{2}{|c|}{ Alternatives } & \multicolumn{4}{|c|}{ Criteria Weights } & \multicolumn{2}{|c|}{ Priorities } \\
\hline & LS & TWA & RE & GPA & TA & BA & \\
\hline & 0.175 & 0.112 & 0.179 & 0.210 & 0.228 & 0.097 & \\
\hline Alt.1 & 0.167 & 0.500 & 0.236 & 0.458 & 0.472 & 0.297 & 0.360 \\
\hline Alt.2 & 0.417 & 0.167 & 0.500 & 0.271 & 0.362 & 0.203 & 0.340 \\
\hline Alt.3 & 0.417 & 0.333 & 0.264 & 0.271 & 0.167 & 0.500 & 0.300 \\
\hline
\end{tabular}

Based on the obtained results, the priority value of Alt. 1 is 0.360 and gains the greatest priority among other alternatives. The main reason of this result is dominating values of Alt. 1 in three criteria including TWA, GPA, and TA. As for Alt. 2 dominates in criterion RE and Alt. 3 dominates in criterion BA. They also hold the advantage in criterion LS compared to Alt. 1. As you see, Alt. 3 has greatest value in the criterion which has the lowest weight. Therefore, Alt. 2 has the overall advantage over Alt. 3.

\section{CONCLUSION}

This study presents an application of intervalvalued intuitionistic fuzzy sets in human resource management. HRM makes critical decisions that could influence the performance of the organization. HRM managers deal with uncertainty in their judgments and confront with hesitant decision especially in personnel selection. We proposed a new application of IVIFS in personnel selection at a university. Linguistic scales of IVIFS enable decision maker to make evaluations comfortably and taking into account his/her hesitancy in evaluations. Then, IVIFS steps could compare alternatives and declare the best alternative. For further research, we suggest hesitant fuzzy sets to be used in HRM.

\section{References}

[1] R. L. Daft, Management, Mason: Cengage Learning, 2009.

[2] Z. Gungor, G. Serhadlioglu and S. E. Kesen, "A fuzzy AHP approach to personnel selection problem," Applied Soft Computing, pp. 641-646, 2009.

[3] V. Kersuliene and Z. Turskis, "An integrated multi-criteria group decision making process: selection of the chief accountant," in Social and Behavioral Sciences, Rome,
2014.

[4] B. Karatop, C. Kubat and o. Uygun, "Talent management in manufacturing system using fuzzy logic approach," Computers \& Industrial Engineering, 2014.

[5] K. T. Atanassov, "Intuitionistic Fuzzy Sets," Fuzzy Sets and Systems, pp. 87-96, 1986.

[6] K. Atanassov, "Interval Valued Intuitionistic Fuzzy Sets," Fuzzy Sets and Systems, pp. 343-349, 1989.

[7] J. Baron and D. Kreps, Strategic Human ResourcesFrameworks for General Managers, New York: Wiley, 1999

[8] A. Golec and E. Kahya, "A fuzzy model for competencybased employee evaluation and selection," Computers \& Industrial Engineering, pp. 143-163, 2007.

[9] B. Daneshvar and T. E. Erkan, "Selection of Academic Staff Using the Fuzzy Analytic Hierarchy Process," Tehnički vjesnik, pp. 923-929, 2012.

[10] V. Shahhosseini and M. H. Sebt, "Competency-based selection and assignment of human resources to construction projects," Scientia Iranica, pp. 163-180, 2011.

[11] A. Kelemenis and D. Askounis, "A new TOPSIS-based multi-criteria approach to personnel selection," Expert Systems with Applications, pp. 4999-5008, 2010.

[12] M. Dursun and E. E. Karsak, "A fuzzy MCDM approach for personnel selection," Expert Systems with Applications, pp. 4324-4330, 2010.

[13] P. T. Chang, L. C. Huang and H. J. Lin, "The fuzzy Delphi method via fuzzy statistics and membership function fitting and an application to the human resources," Fuzzy Sets and Systems, pp. 511-520, 2000.

[14] A. Kelemenis, K. Ergazakis and D. Askounis, "Support managers' selection using an extension of fuzzy TOPSIS," Expert Systems with Applications, pp. 2774-2782, 2011.

[15] E. Aksakal, M. Dagdeviren, E. Eraslan and I. Yuksel, "Personel Selection Based on Talent Management," in Social and Behavioral Sciences, Budapest, 2013.

[16] J. Wu, H. B. Huang and Q. W. Cao, "Research on AHP with interval-valued intuitionistic fuzzy sets and its application in multi-criteria decision making problems," Applied Mathematical Modelling, pp. 9898-9906, 2013. 